\title{
AGGREGATOR AS COST OPTIMIZATION TOOL FOR ENERGY DEMAND
}

\author{
Madara Zvirgzdina $^{1}$, Olga Bogdanova ${ }^{1}$, Jurijs Spiridonovs ${ }^{2}$ \\ ${ }^{1}$ Riga Technical University, Latvia; ${ }^{2}$ Riga International School of Economics and Business \\ Administration, Latvia \\ madara.zvirgzdina@gmail.com, nameolga@yahoo.co.uk, j.spiridonovs@gmail.com
}

\begin{abstract}
Historically, the absolute price flexibility and perfect competition was always considered as purely theoretical issue. Even in well developed markets flexibility of demand is usually hindered by lack of information on differences in offers available on the market. Similar pattern characterises power market as well. Electricity users are usually consuming the same amount of power regardless the changes of the power price, which makes the electricity consumption inelastic to the electricity price. Consequently, to meet a given demand, the same constant volume has been classically ensured on supply side by stable centralized power generation. However, due to climate protection policy the share of renewable energy sources in power generation is growing rapidly. It means more variable energy supply and more explicit electricity price fluctuations. The development of smart technologies and aggregation tools ensure a great opportunity to adjust the electricity consumption to the generated energy in a certain time. In this way, the available energy sources can be used to their fullest potential, the electricity system can be stabilised by levelling out the peak load hours and the electricity prices can be stabilised avoiding big fluctuations. The aim of the research is to analyse aggregators as a tool to facilitate power price flexibility through electricity demand response development, therewith demonstrating how the classical principle of economics' theories on demand-supply flexibility find their practical application. In the research generally accepted quantitative and qualitative methods of economic science, comparative analysis, statistical data processing, synthesis, inductive, deductive, logically constructive, parameter estimation and economically mathematical modelling methods are applied.
\end{abstract}

Keywords: aggregation, optimization, electricity, demand response.

\section{Introduction}

Nowadays electricity still can be stored in an economically viable way with the severe limitations in volumes. Therefore, the power system has to ensure equal amount of generated and demanded energy. In general, the energy consumption volume directly correlates with the economic development of a country. Although being traded on a market, de facto the amount of the electricity demanded is inelastic to the electricity market prices. Power users usually do not change power consumption patterns due to the electricity price, as it takes time and knowledge for them to follow the price changes on the market and effort to make changes in their busy daily life. Therefore, the electricity price tends to go up in the peak hours, when the demanded amount of energy cannot be generated using only cheaper generation facilities and more expensive generators are activated to meet the demand. Historically, energy power generation was centralized and was quite a stable process, as it used to be generated in large power stations, from where the electricity was further transmitted geographically [1]. Due to the recent developments, countries around the world are challenged by the $\mathrm{CO} 2$ emissions' reduction and therefore working to increase the renewable energy share. Therewith, the sustainable energy generation and energy efficiency are considered as important mechanisms reaching the goals set in the Paris Climate Agreement [2;3]. In the power market variable energy generation causes fluctuation in the energy supply, which makes the system more unstable increasing the need for the system operators to be able to manage and level the demand and supply of electricity in the system.

The aim of the research is to analyse aggregators as a tool to facilitate power price flexibility through electricity demand-response development, therewith demonstrating how the economics theory on demand-supply flexibility could be practically applied in the power sector. Practically, aggregator is a software, adjusting the pattern of consumption of a given client due to the changes on a power marketwith a help of an aggregation appliance installed at electricity consumption place.

For the research the authors applied quantitative and qualitative methods of economic science, comparative analysis, statistical data processing, synthesis, inductive, deductive, logically constructive, parameter estimation and economically mathematical modelling and other methods. All the calculations provided in the paper are based on the real data for on hourly power prices and trading volumes in Latvia available on the NordPoolpower exchange data base. 


\section{Scientific justification of the research}

According to the economic theory, the perfect competition ensures absolute elasticity of supply and demand curves in case of changes in price. One of the important preconditions for perfect competition isabsolute availability of informationto buyers and sellers about the price, product and the trading methods [4]. As it is almost impossible to ensure the perfect information availability, the perfect competition model has always been considered as purely theoretical.

However, the power sector currently experiences rapid development. The cross-border power network is well developed, the authorized power frequency range (with a minimal fluctuation allowed by the Network Code) standardizes power (product) quality; the power trading methods are more transparent, as all the market players of the region are obliged to usefor trade an electronic bidding system of NordPool power exchange for their commercial transactions. Due to the development of technologies, consumers have a possibility to get an instant access to the market information and adjust their demand accordingly. Moreover, smart technologies provide consumersan option to take on a completely new role and be active in the market, providing the saved electricity to others by adapting their electricity consumption to the electricity market needs. With such renewable energy generation technologies, as solar panels, wind turbines etc., individual households, industrial users, and farmers can now also produce their own electricity feeding it back into the grid. Decentralized power generation with large number of flexible generators and flexible consumers applying demand response management that aggregators can offer, could considerably contribute to the electricity market stability $[5 ; 6]$.

For an average consumer the demand response or consumption adjustment to constantly floating power price might seem to come with risks and complexities. Therefore, the process could be managed by the aggregators. The aggregators change the power consumption or generation (in case of local generation) patterns according to the price changes [7]. So-called "supply aggregators" and "demand aggregators" pro-actively engage technologies located at consumer properties or aggregate demand side services across a number of customers. Aggregation can be used as a tool to efficiently balance the power flows, gathering different consumer ability to change their consumption patterns.[8]Aggregators collect the energy that the supplier has purchased for its clients in anticipation of their needs and resell it to the market. Taking into account that the energy market is based on the concept that consumers in any time can use their anticipated power amount, this amount of energy is kept ready to supplying case the consumer starts using it. Though the aggregator's "product", using its ability to enable the suppliers' customers to reduce their demand and gather this unused energy, offers a product to the market that removes the need to generate an equivalent amount of energy. As in the energy market no more energy can be generated than is consumed, the aggregator's product reduces the amount of the energy generated.

According to the economics theory, changes in demand or supply shift the market equilibrium causing changes in the market price and product quantities [9]. Managed consumer demand response of energy with effectively applied costs can reduce the wholesale market prices leading to a significant social benefit. In the energy market, even the slightest changes can provide the possibility to avoid high marginal costs in times, when the supply-demand is intense.

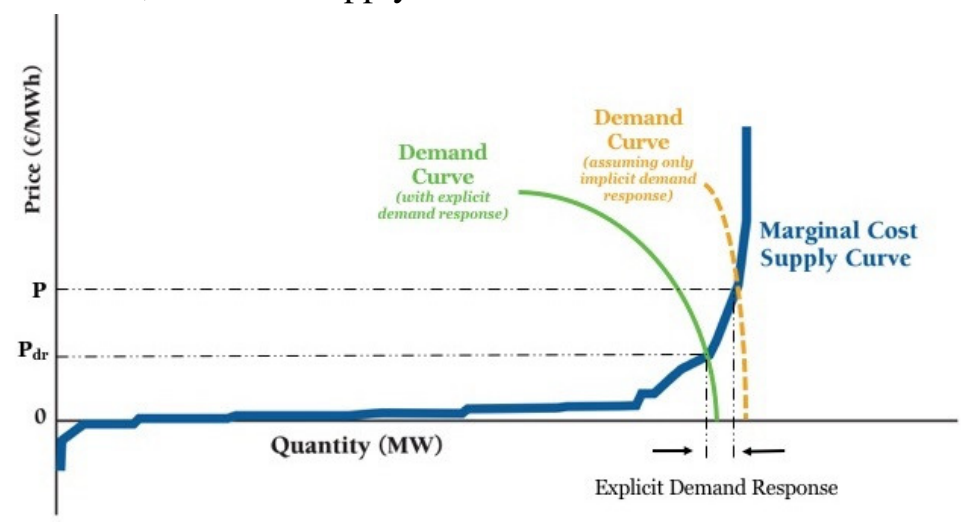

Fig. 1. Explicit demand response reduces wholesale electricity prices [10] 
As Figure 2 demonstrates, if the demand is decreased in certain time periods, when the supply is scarce, then using the aggregator ability to manage the demand response the price increase can be avoided. Changes in the demand curve moving it to the left and causing the power price decrease from $\mathrm{P}$ to $\mathrm{P}_{\mathrm{dr}}$ shows that suppliers are able to buy energy cheaper for their clients. As a result, demandsupply management can provide a genuine societal benefit in lower wholesale and retail energy prices avoiding also uneconomic network investments.

The aggregation technology ensures a possibility to manage demand response in different ways either decreasing the demand or delaying it. In the first situation, the consumers are stimulated to switch their electricity consuming devices off for a certain period during the day, which means that the amount of the consumed electricity decreases. In the other situation, the consumer delays to turn a certain electricity consuming device on for a certain period and is invited to turn it on in a different time, when the supply is durable comparing to the overall demand, which mostly means that the prices of the electricity are lower. In this situation the overall amount of the consumed electricity does not change. However, even without decreasing the demand the overall costs of the same amount of the consumed electricity can be lowered.

Within the research, the authors practically estimate the potential economic benefit the aggregation technology could bring to the market participants and economy in general. The research is based on the data of Latvia; however, the same methodology could be applied also to other countries and economies with a functioning electricity market.

\section{Methodology of the research}

For the research the authors used the primary data source - historical data on hourly power prices and trading volumes in Latvia available on the NordPool power exchange data base. The data were mathematically proceeded by Excel tool using the equations provided further in the text.

In order to assess the benefits aggregators could bring, within the research, the authors gathered and estimated the quantitative data to identify to which extend the changes in demand influence the power consumption costs. To calculate the total power costs of regular power consumer (without aggregator) per month the quantitative data on power consumption (MWh) in Latvia and power prices in the Latvia's price zone per hour in October 2017 were collected from the Nord Pool power exchange data base.

The total power consumption costs per hour are calculated applying parameter estimation and economically mathematical modelling methodkeeping constant power consumption time and volume during the given month, multiplying the consumption by average hourly power price of the month (see Equation 1).

$$
L_{a v}=\sum\left(P_{a v} \cdot \sum E_{a v}\right)
$$

where $L_{a v}-$ total costs of power consumer per months, EUR;

$P_{a v}-$ average power price in Nord Pool in a given hour during the entire month, EUR. $(\mathrm{MWh})^{-1}$;

$\sum E_{a v}$ - average sum of consumed power volume each hour during the entire month, MWh.

According to the assumption of the research, due to the aggregation activity, the power consumption of a customer was shifted in time, consuming the same amount of power, but in other time (see Fig. 2).

As it is shown in Figure 2, within the research, the authors by Excel tool shiftedpower consumption datafrom the peak load of the system for one hour to a lower estimated power price time - the consumption of power from 1:00-2:00 (Central European Time) was moved to 2:00-3:00, but the consumption of power from 2:00-3:00 was moved to 3:00-4:00, etc. For the cost analysis, the total volume of power consumed is calculated with an assumption that the power prices remain the same, as no consumption shift has happened.

The authors calculated the total cost savings summing up the costs of each power consumption hour each day after one-hour shift and removing them from the total costsof power consumed (see Equation 2). 


$$
I_{\text {with }} \text { shift }=\sum(P \cdot I)-\sum\left(P \cdot E_{\text {hshiff }}\right)
$$

where $I_{\text {with h shift }}$ - total cost savings, if the consumption is shifted by one hour, EUR;

$P$ - power price in Nord Pool in a given hour, EUR. $(\mathrm{MWh})^{-1}$;

$E$ - consumed power volume in a given hour, MWh;

$E_{h \text { shift }}$-consumed power volume in an hour that is shifted forward.

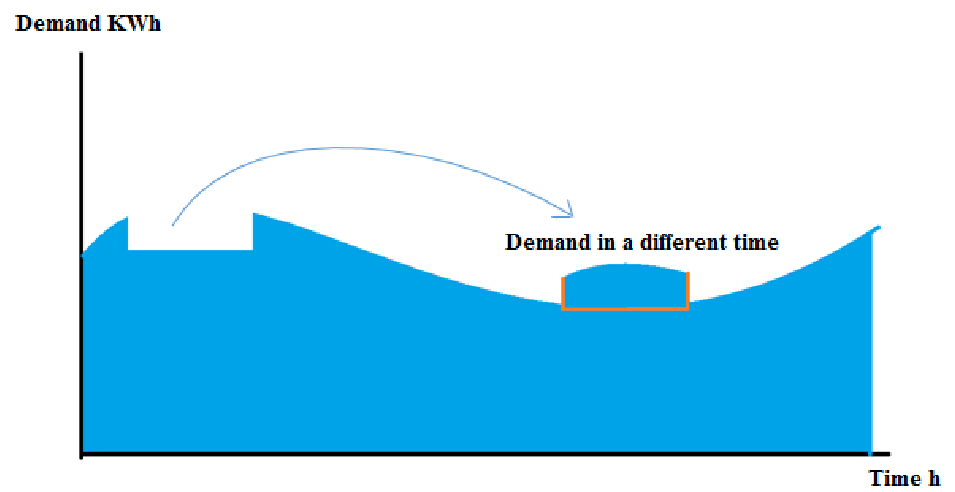

Fig. 2. Change of power consumption period [11]

Taking into account that according to the demand/ supply flexibility rule the consumption volumes increase, when prices are going down[4], the authors calculated the average next day price assuming that the consumption (being affected by aggregator) decreased by $5 \%$ every hour, when price was above the average power price.

The authors calculated the total saved (not produced) energy during the peak load, when the power price is above average, using equation 3 .

$$
S_{a v}=\sum\left(100-\left(\sum E_{1} \cdot 100\right) / \sum E\right) / n
$$

where $S_{a v}$-average energy savings in percentage;

$n$ - number of days, in which the consumption percentage has been calculated;

$E$ - sum of consumption per day, MWh;

$E_{1}-$ sum of consumption per day with $5 \%$ decrease in consumption in times, when prices are above average, MWh.

The authors calculated the total economic benefit from application of the aggregation tool for energy consumption shifting to lower price periods (applying Excel tool to historical data available on NordPool data base) with a help of mathematical programming method, assuming that maximum flattened prices, which could be reached thanks to demand response reaction, are stabilized.

To calculate the total economic benefit from aggregators, the authors analysed hourly data from the Nord Pool power exchange on the consumption and price for each first day of the first full week of a month during entire 2017. The calculation is performed using equation 4.

$$
S_{\max }=\sum(E \cdot P)-\sum\left(E \cdot P_{a v}\right)
$$

where $S_{\max }-\max$ possible savings with levelled supply demand;

$E$ - consumption per hour a day, MWh;

$P$ - electricity price per hour a day, EUR $(\mathrm{MWh})^{-1}$;

$P_{a v}-$ average electricity price, EUR $\cdot(\mathrm{MWh})^{-1}$.

The result demonstrated the energy costs savings for 84 days (2016 hours). Consequently, to calculate the annual data, it was adjusted proportionally to the amount of the days in 2017 (365 days).

\section{The results of the research}

According to the methodology described in the paper,the authors estimated the economic impact of the aggregation tool on the Latvian power market and economy.

Applying Equation 1 to the historical data on the power price and consumption available on the NordPool data base [12], the authors calculated the total expenditure for power in Latvia in October 2017, it was 21946772.89 EUR. 
The costs savings for the power consumed after the shifting consumption by one hour can reach up to 5000 EUR per day. However, the total costs savings calculated by the authors applying equation 2 to the historical data available on the NordPool data base [12] are 50523 EUR.

This calculation shows that without changing the amount of the power consumed, but just shifting it in time, the electricity consumption costs can be considerably decreased. In Figure 3 the authors demonstrate the two days changes in the costs because of shifting the consumption time by one hour in Latvia.

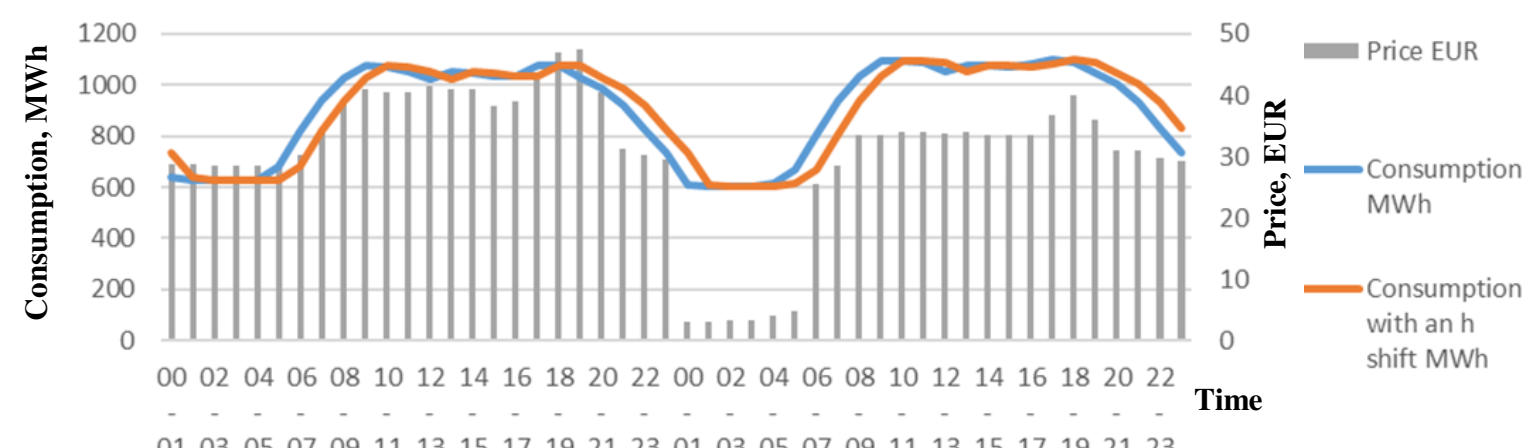

Fig. 3. Costs of power with and without consumption shifting in time

Figure 3 proves that by adjusting their consumption habits consumers can optimize spending and network load.

However,assuming that aggregators arehelping consumers to decrease the demand in specific periods during the day -in the peak hours and at the times, when the power prices are above the average, the calculation decreasing consumption by $5 \%$ every hour, when the prices of the electricity were higher than the average price of the day, is performed. Using this simulation of the demand response management by aggregators the authors using the historical data available on the NordPool data base [12] calculated (equation 3) that in average a day the demand was decreased by $3 \%$,bringing up in average 25000 EUR savings a day.

The total annual savings of economy that aggregators can potentially bring thanks to flattering the peak power prices in a market calculated by the authors using the historical data available on the NordPool data base [12] and applying equation 4 are 8432356 EUR.

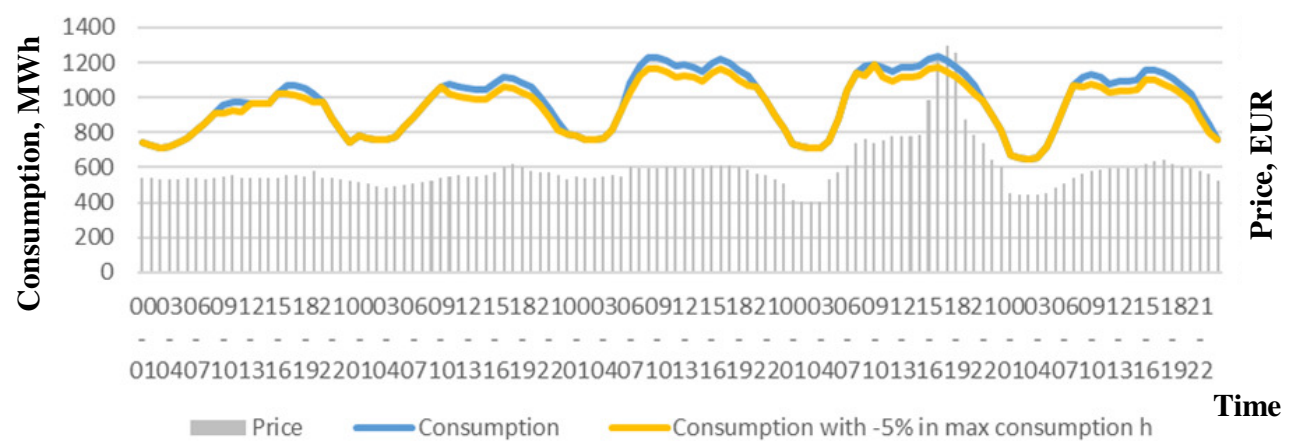

Fig. 4. Correlation ofpower consumption from price due to demand response reaction

As demonstrated in Figure 4, using the aggregatorsand demand response,the necessary demand reduction can be gathered from various consumers, therefore, the amount can be of a value, when adjusting the consumption to the supply capacity in the peak hours lowering the overall electricity price.

\section{Conclusions}

The research practically demonstrates that application of the aggregation tool in the power sector brings a range of benefits to individual power consumers and the economy in general:

- the aggregation tool decreases the costs of a power consumer participating in demand response management; 
- the aggregation tool facilitates decrease of total power price on a market as due to optimal distribution of power demand within time more expensive power generators are not activated;

- by lowering the network load, the overload of transmission network decreases eliminating the risk of cross-border congestions for cheaper price flows;

- the aggregation tool decreases the power consumption costs for all the economy making economy more cost efficient and competitive;

- the aggregation tool facilitates reaching the targets of the Paris Climate Agreement.

\section{References}

[1] Spiridonovs J., Bogdanova O., EU Energy Union: adjustment to the new development cycle. Copernican Journal of Finance \& Accounting. Volume 6, Issue 1, 2017 quaterly. - Torun: Nicolaus Copernicus University, 2017, pp. 89-102. e-ISSN: 2300-3065, p-ISSN: 2300-1240. (ERIH PLUS)

[2] Spiridonovs J., Bogdanova O., The resilient Energy Union - response to the challenges of XXI century. Proceedings of selected papers of 21st International Scientific Conference Economics and Management. Smart and Efficient Economy: Preparation for the Future Innovative Economy. - Brno: Brno University of Technology, Faculty of Business and Management, 2016, pp. 409-415. ISBN 978-80-214-5413-2.

[3] Jirusek, M., Vlcek, T., Kodouskova, H. (2015) Energy Security in Central and Eastern Europe and the Operations of Russian State-Owned Energy Enterprises 337-688p.Masarykovauniverzita, Brno, ISBN 978-80-210-8048-5.

[4] Nešpors V. Ievads mikro-ekonomikas teorijā (Introduction to the theory of microeconomics)145 p. (In Latvian), Kamene, ISBN10:9984636525, 2003.

[5] Regulatory Recommendations for the Deployment of Flexibility (2015). EG3 Report smart grid task force [online] [20.09.2017]. Available at:

https://ec.europa.eu/energy/sites/ener/files/documents/EG3 \%20Final \%20-

\%20January \%202015.pdf

[6] Existing business models for renewable energy aggregators. BestRES - Best practices and implementation of innovative business models for Renewable Energy aggregators, 2016. [online][06.06.2017]. Available at:

http://bestres.eu/wp-content/uploads/2016/08/BestRES_Existing-business-models-for-REaggregators.pdf

[7] Baker P. (2017). Unleashing Demand Response with Effective Supplier Compensation. The Regulatory Assistance Project (RAP), June 2017 [Online] [01.10.2017]. Available at: http://www.ourenergypolicy.org/wp-content/uploads/2017/06/rap-baker-unleashing-demandresponse-effective-supplier-compensation-2017-june.pdf

[8] Kempener R., Malhotra A., de Vivero G. The age of renewable power, designing national roadmaps for a successful transformation (2015). International Renewable Energy Agency report [Online] [27.10.2017]. Available at:

https://www.irena.org/DocumentDownloads/Publications/IRENA_PST_Age_of_Renewable_Pow er_2015.pdf

[9] Bikse V. Ekonomikas teorijas pamati (Basics of Economic Theory), Rīga: SIA “Izglītībassolıli”. 2007, 114 p. (In Latvian).

[10] Baker P. Proposed Electricity Directive a Step in the Right Direction for Customers, Demand Response. The Regulatory Assistance Project (RAP), 2017. [online] [03.10.2017]. Available at: http://www.raponline.org/blog/proposed-electricity-directive-step-right-direction-customersdemand-response/

[11]Designing fair and equitable market rules for demand response aggregation. A Eurelectric 2015 paper [Online] [28.10.2017]. Available at: http://www.eurelectric.org/media/169872/ 0310_missing_links_paper_final_ml-2015-030-0155-01-e.pdf

[12] Nord Pool Power exchange data base.[online] [03.10.-10.01.2018]. Available at: https://www.nordpoolgroup.com/ 